acceptance by the organizing committee of the meeting. Due emphasis is given to the generous aid received from the Ford and Rockefeller Foundations of the United States which has enabled the Council to extend considerably its fellowship programme and has helped to finance some of the activities already mentioned.

A brief analysis of the Council's budget for the fiscal year which ended on October 31, 1961, shows that the amount budgeted was Argentine pesos $211,386,009,90$ (about $£ 1$ million at the then prevailing rate of exchange). Expenditures for the same period did not amount to the total budgeted, and it is note. worthy that administrative expenses amounted to only 8 per cent of the total expenditure.

During 1961, the Council resolved to buy a building in order to have more adequate premises. The future address is Rivadavia 1917, Buenos Aires, Argentina, where the Council expects to move before the end of the year, once the necessary alterations have been completed.

In the final part of the report, overall aspects of the Council's task are given consideration. They can be summed up by the considerable increase of young scientists adequately trained for research; the larger volume of research work undertaken in Argentina with the aid of Council funds granted to institutions and scientists; the establishing of new research teams and research contres and the higher level attained by research work in different fields. It is emphasized that the activity of the Council, combined with that of some other institutions carried out along similar lines in the past few years, has established a most favourable environment for original and creativo scientific research by fostering the general interest in scientific activity and obtaining increased aid for its continuation from official quarters as well as from the general public.

\title{
CYTOCHEMICAL PROGRESS IN ELECTRON MICROSCOPY
}

$\mathrm{T}$ HE symposium on "Cytochemical Progress in Electron Microscopy", which was held by the Royal Microscopical Society in Oxford during July 2-4, was a success both in the size of the attendance and the interest of the topics. The majority of those attending were British, but several papers were submitted from France and others from Belgium, the United States, Holland and Sweden.

The information presented fell into four categories. (1) Effects of different fixatives, embedding media and electron-absorbing 'stains' on morphological detail. (2) Sub-microscopic localization of enzymes utilizing electron-absorbing cytochemical reaction products. (3) The effects on morphological detail of extraction by chemical or onzymatic reagents. (4) Autoradiography at electron-microscope magnifications. It is a pity that the symposium was not organized to present consecutively the papers covered by these or similar headings. As it was, the fragmentation of discussion of any one topic prevented the important points resulting from it from being clearly presented to the non-specialist in the audience.

Under the first of the headings which I have chosen here, Dr. W. Bernhard and Dr. Elizabeth Leduc (Villejuif, France) presented beautiful pictures of the striking difference in appearance produced in tissues embedded in water-soluble glycol-methacrylate, compared with those embedded in media soluble only in organic solvents. 'These results were enlarged on by Dr. V. Marinozzi (Villejuif), who presented much useful information on differences produced by fixation in various solutions and embedding in different non-water-soluble media. Much technical information will be available as a result of the investigations of Dr. J. Sikorski (Leeds) on keratinous cells, of Dr. J. R. Casely-Smith (Villejuif) on fixation and staining of lipids, and of Dr. E. H. Mercer (London) and Drs. W. Th. Daems and J. P. Persijn (Leydon, Holland) on 'stains' for electron microscopy. The papers of Drs. E. L. Benedetti and B. Bertolini (Amsterdam), on the use of phosphotungstic acid as a stain for the plasma membrane, and Dr. R. L. Tapp (Cambridge), on the fine structure of desmosomes after a variety of techniques, illustrated the necessity of studying cell structure after using a variety of methods of preparation before attempting to interpret the functional significance of the details detected.

The value of using light-microscopy to investigate material and the changes which occur in it during preparation for electron microscopy was underlined by the papers of Prof. N. A. Barnicott (London) and Dr. H. E. Huxley (Cambridge) on their investigations of chromosomes and Dr. H. G. Davies (London) on his experiments with erythrocyte nuclei. It is to be hoped that the structureloss nature of the chromosomes which was so beautifully displayed may be due to fixation artofacts as was suggested by the information provided by Dr. B. M. Richards (London) in the discussion.

The most striking results in cytochemical investigations at the electron-microscope level have been those of the American and German workers using enzyme reaction products containing heavy metals. In the absence of these original contributors Dr. A. ( ${ }_{x}$. E. Pearso (London) gave a lucid account of the possibilities of this approach. He pointed out the incompatibility of good osmium fixation and the preservation of some enzymes, but also indicated that a method giving a bad picture at the light-microscope level might give a good one in the electron microscope. $\mathrm{He}$ also warned that much shorter incubation of tissues in substrates would probably be required if good electron micrographs devoid of diffusion of reaction product were to be obtained. Drs. S. J. Holt and Marian Hicks (London) illustrated many of these points with their paper on the localization of acid phosphatase in lysosome-like particles. Drs. G. de Thé, A. B. Novikoff and J. W. Beard (North Carolina) showed among other things that virus particles on entering and leaving a cell not only acquired a covering of part of the cellular membranes but also the adenosine triphosphatase activity associated with these membranes. It is this sort of result which makes the detailed work of eytochemistry at the electron-microscope level worth while. Dr. B. Boothroyd (Liverpool), in his paper on the effect of electron irradiation on glycogen, showed pictures of this polysaccharide stained by the periodic acidSchiff technique, which illustrates that deposition 
of sufficient organic stain at a locus may sufficiently raise its electron-absorbing properties as to give good eontrast in the electron microscope. This has already been found to be the case at ultra-soft $\mathrm{X}$-ray wave-lengths, and some preliminary work suggests that heavy metals need not be incorporated into enzyme reaction products in order to make them absorb electrons sufficiently.

The use of extraction methods, and biochemical and cytological control of the extraction process, were well illustrated by Drs. S. and M. Nass (Stockholm), who postulated that a deoxyribonucleic acid-like matorial was present in mitochondria. Drs. R. R. Dourmashkin, R. M. Dougherty and R. J. C. Harris (London) presented their superb pictures of the pits or holes in virus and cell membranes after these had been extracted with saponin and digitonin.

The introductory review by Dr. S. R. Pelc (London) on the theory of autoradiography presented the background to the limitations of the use of conventional photographic emulsions in studying isotope localization with the electron microscope. Drs. G. A. Meek (Oxford) and M. J. Moses (North Carolina) presonted oxcellent pictures of the localization of ${ }^{3} \mathrm{H}$-thymidine in HeIa cells. Dr. P. Granboulan (Villejuif) discussed the resolving powor and sensitivity of some new emulsions and showed autoradiographs with extremely small grains $(0 \cdot 1 \mu)$. Dr. $H$. Firket (Liège), working in conjunction with Dr. Granboulan, showed the result of the use of these emulsions in studying the incorporation of ${ }^{3} \mathrm{H}$ uridine in colls. A lively discussion followed all these papers and the questions of resolution (spatial relation between developed grain and omitting particle) and the probability of biological significance of a few devoloped grains overlying cellular structures were widely debated. It appears that progross in this branch of electron microscopo cytochemistry will depend on the exploitation of photosensitive layers other than silver halide-gelatin omulsions and the use of less-conventional methods of development. These methods have been described in the literature of photographic processes.

Presentation of the use of the electron microseope for studying the localization of antigens in cells by staining them with antibody conjugated to ferritin was made by Miss Jane Baxandall and Drs. P. Perlmann and B. A. Afzelius (Stockholm) and by Dr. Margaret Mott (Edinburgh). These methods appear to permit localization of substance on the surface of the cells, but the contrast of the conjugate is so low as to give a rather unconvincing picturo. 'This is another case where 'chromaticity' in the electron microscopo would be useful in identifying the iron component of the conjugate.

The contrast of the modern approach used by the contributors and the near-medieval surroundings in which they were lodged during the conference was even greater than that between the excellent now lecture theatre in which the scientific sessions were held and the fabric of the University Museum which contains it. It is to be hoped that the Royal Microscopical Society will before long present another symposium of such topical intorest.

The communications will be publishod in detail in the Society's Journal by the end of this year. A. J. H.

\section{RADIO RESEARCH I96I}

$I^{N}$ the previous report of the Radio Research Board, it was noted that Mr. J. A. Ratcliffe took over his duties as director of the Radio Research Station on October 1, 1961 (see Nature, 185, 354; $1960: 191,1255 ; 1961)$. The report for 1961 has now becomo available*.

This report describes the action that has been taken to implement earlier decisions to devote half the effort available to the Radio Rosearch Station to a programme of space research : and by this is meant the use of sounding rockets and satellites to carry out fundamental investigations of the upper atmosphere and ionosphere, and of the factors which determine the behaviour of these media for transmitting radio waves.

For many years past the work of the Radio Research Station has included detailed measurements of the properties of the ionosphere and the application of the results to the study of the propagation of highfrequency radio waves over long distances. Charts are now available giving detailod characteristics of the $F^{r}$ region of the ionosphere for the conditions of maximum and minimum solar activity. By sensible extrapolation, these can be used to calculate the transmission characteristics required for various point-to-point communication services. Experiments are in hand to check these calculations by a pulse transmission technique between Slough and Now Delhi-a distance of some $7,000 \mathrm{~km}$.

* Department of Scientific and Industrial Research. Radio Research 1961: The Report of the Radio Research Board and the Report of the Director of Radio Research. Pp. iv $+27+4$ plates. (London:
H.M.S.O., 1962.) 3s. net.
In parallel with this work, which is based on investigations of the ionosphere from below, the facilities provided by radio transmissions from rockets and satellites are now being used to explore the ionosphere above the height of peak ionization. Two methods are in use for observing the waves transmitted downwards from an artificial satellite at a height of several hundred kilometres. In the first, measurements are made at Slough and Singapore of the Faraday rotation of the plane of polarization of a wave transmitted through the ionosphere. The second method in use at Slough records the Doppler shift on two harmonically related frequencies due to the motion of the satellite. The result is used to calculate the total electron content in the ionosphere.

This work makes use of the facilities now availabe at Winkfield, near Slough, for the tracking of American satellites and the recording of the telemetry signals received from them. The same equipments, together with the corresponding installations at Singapore and Port Stanley, are being used for co-operating in the British experiments now in progress with the American satellite $S-51$, which was planned for investigations organized by the British National Committee on Space Research. Preparations are also well advanced to enable all three of the above stations to participate in the reception of the telemetry signals from the United States and Canadian 'topside sounding' satellites. The purpose of these satellites, expected to be launched in the near future, is to study the characteristics of the 